\section{Acute Leukemia with a typical Clinical Presentation Posing Diagnostic Dilemma}

\author{
Tanushri Mukherjee ${ }^{1 *}$, Suman Pramanik ${ }^{2}$ and Rajat Dutta ${ }^{3}$ \\ ${ }^{1}$ Department of Oncopathology, Command Hospital, Kolkata, India \\ ${ }^{2}$ Department of Haematology, Command Hospital, Kolkata, India \\ ${ }^{3}$ Department of Surgery, Command Hospital, Kolkata, India
}

\begin{abstract}
Background

Acute leukemia presenting as hypocellular leukemia is atypical in presentation and poses diagnostic dilemma and important to differentiate from hypoplastic myelodysplastic syndrome and a plastic anemia as the treatment differs. Hypocellular acute leukemia is defined as more than $20 \%$ blasts in PBS and bone marrow with pancytopenia in peripheral smear and less than $20 \%$ cellularity in the bone marrow. Acute lymphoblastic leukemias in $8-12 \%$ cases present with pancytopenia and $2 \%$ with hypocellular bone marrow. Acute myeloid leukemia presenting in hypocellular form is usually in less than $10 \%$ of all cases of acute myeloid leukemia. Clinical features, peripheral blood, bone marrow aspirate and biopsy and flow cytometric studies substantiate the diagnosis.

\section{Methods}

We studied the acute leukemias with atypical presentation clinical details, blood counts, bone marrow and flow cytometric studies that were later confirmed to be hypocellular acute myeloid and lymphoblastic leukemia.

\section{Results}

Retrospective analysis of clinicohematologic profile of thirty patients of atypical leukemia were done out of total three hundred cases of acute leukemia. Twenty five $(n=25)$ of the thirty cases of hypocellular leukemia were AML with median age 44.36 yrs and male to female ratio of 2:1 and most common presenting complaint of anemia and five cases of hypocellular ALL $(n=5)$ with median age $8 \mathrm{yrs}$ and male to female ratio of $4: 1$ and most common presenting complaint being fever.

\section{Conclusion}

Diagnosis of acute leukemia poses a challenge when there is pancytopenia on peripheral blood and bone marrow cellularity is low and urgent and prompt diagnosis is mandatory for institution of appropriate therapy.

${ }^{*}$ Corresponding author: Tanushri Mukherjee, Department of Oncopathology, Command Hospital, Kolkata, India, Tel: +91 8697980702; E-mail: tanujamukherjee@yahoo.com

Citation: Mukherjee T, Pramanik S, Dutta R (2016) Acute Leukemia with Atypical Clinical Presentation Posing Diagnostic Dilemma. J Hematol Blood Transfus Disord 3: 010.

Received: June 09, 2016; Accepted: August 29, 2016; Published: September 12,2016

\section{Introduction}

Acute leukemia presents with more than $20 \%$ blasts in the bone marrow with hypercellularity usually. However acute leukemia presenting with a hypocellular bone marrow and pancytopenia is atypical in presentation and creates difficulty in diagnosis and treatment and it is important to differentiate from Myelodysplastic syndrome and a plastic bone marrow as the treatment differs and prognosis varies. Hypocellular acute leukemia is defined as more than $20 \%$ blasts in PBS and bone marrow with pancytopenia in peripheral smear and less than $20 \%$ cellularity in the bone marrow. Acute lymphoblastic leukemias in $8-12 \%$ cases present with pancytopenia and $2 \%$ with hypocellular bone marrow. Acute myeloid leukemia presenting in hypocellular form is usually in less than $10 \%$ of all cases of acute myeloid leukemia. Clinical features, peripheral blood, bone marrow aspirate and biopsy and flow cytometric studies substantiate the diagnosis. We carried on this retrospective analysis to see the clinical, hematological and immunophenotypic patterns with the response to therapy.

\section{Materials and Methods}

This is a retrospective observational study of 30 cases of freshly diagnosed case of acute leukemias that presented with hypocellularity in the bone marrow in an atypical way in duration from 13 May 2013 - 12 May 2016. Clinical history, age, presenting complaints, drug and medication history and laboratory parameters were all compiled. Complete Peripheral blood count smear and bone marrow aspirate smears were studied. Myeloperoxidase and Periodic Acid Sciff (PAS) was performed on the smears. Bone marrow trephine biopsy assessed for cellularity and blasts and marrow fibrosis was graded by doing reticulin stain. Flow cytometry analysis was performed on peripheral blood and bone marrow aspirate.

\section{Results}

Out of total three hundred cases of acute leukemia, we found thirty cases of hypocellular bone marrow with less than $20 \%$ cellularity and more than $20 \%$ blasts that is $10 \%$ of all cases of acute leukemia. Twenty five $(n=25)$ of the thirty cases of hypocellular leukemia were AML (8.3\% of the total diagnosed cases of acute leukemia) with median age $44.36 \mathrm{yrs}$ and male to female ratio of 2:1 and most common presenting complaint of pallor and anemia and five cases of hypocellular ALL $(n=5)(1.3 \%$ of all diagnosed cases of acute leukemia with median age 8 yrs and male to female ratio of $4: 1$ and presenting complaint being fever in 3 cases and lymphadenopathy in 1 case and mediastinal mass in one case and they presented with pancytopenia in peripheral blood and with hypocellular bone marrow with cellularity (Figure 1) less than $20 \%$ and does not fit into the WHO defining criteria of acute leukemia but flow cytometric analysis (Figure 2) confirmed the blasts as described below and the diagnosis was consistent with acute lymphoblastic leukemia. The mean hemoglobin was $5.98 \mathrm{gm} / \mathrm{d}$. The mean white blood cell count was $1.2 \times 10^{9} / \mathrm{L}$ (range $1.0 \times 10^{9} / \mathrm{L}-2.0 \times 10^{9} / \mathrm{L}$. Patients with hypocellular AML had lower white blood cell counts $(P<0.0001)$ and hemoglobin concentrations $(P<0.0001)$ at presentation. The mean bone marrow cellularity of $11 \%$ (range, $6-16 \%$ ). In our study of 30 cases of hypocellular acute leukemia in three years 
Citation: Mukherjee T, Pramanik S, Dutta R (2016) Acute Leukemia with Atypical Clinical Presentation Posing Diagnostic Dilemma. J Hematol Blood Transfus Disord 3: 010.

- Page 2 of 4 •

\begin{tabular}{|c|c|c|c|c|c|c|c|c|c|c|c|c|}
\hline Case & $\begin{array}{l}\text { Age } \\
\text { (Yrs) }\end{array}$ & Gender & $\begin{array}{l}\text { Presenting } \\
\text { complaint }\end{array}$ & $\begin{array}{l}\text { Hemoglobin } \\
(\mathrm{mg} / \mathrm{dl})\end{array}$ & $\begin{array}{l}\text { TLCl } \\
\text { cumm. }\end{array}$ & $\begin{array}{l}\text { Blast in } \\
\text { Peripheral } \\
\text { blood }\end{array}$ & $\begin{array}{l}\text { Bone } \\
\text { marrow } \\
\text { blast }\end{array}$ & $\begin{array}{c}\text { Bone } \\
\text { marrow } \\
\text { biopsy } \\
\text { cellularity }\end{array}$ & $\begin{array}{c}\text { Reticulin } \\
\text { fibrosis } \\
\text { grade }\end{array}$ & Flow markers + & $\begin{array}{l}\text { WHO } \\
\text { criteria }\end{array}$ & $\begin{array}{l}\text { Treatment } \\
\text { and follow } \\
\text { up. }\end{array}$ \\
\hline 1 & 45 & Male & Pallor & 7.8 & 1 & 2 & 12 & 14 & 1 & $\begin{array}{l}\text { CD!3,CD33,CD117,M- } \\
\text { PO,CD45,HLADR }\end{array}$ & AMLM1 & Follow up \\
\hline 2 & 43 & Male & Pallor & 4.6 & 2 & 2 & 20 & 15 & 1 & $\begin{array}{l}\text { CD!3,CD33,CD117,M- } \\
\text { PO,CD45,HLADR }\end{array}$ & AMLMO & Follow up \\
\hline 3 & 44 & Female & Epistaxis & 10 & 1.5 & 3 & 13 & 15 & 2 & $\begin{array}{l}\text { CD!3,CD33,CD117,M- } \\
\text { PO,CD45,HLADR }\end{array}$ & AMLM4 & Death \\
\hline 4 & 45 & Male & Pallor & 6.5 & 1 & 1 & 18 & 11 & 1 & $\begin{array}{l}\text { CD!3,CD33,CD117,M- } \\
\text { PO,CD45,HLADR }\end{array}$ & AMLM1 & Follow up \\
\hline 5 & 51 & Male & Pallor & 5.5 & 2 & 2 & 21 & 11 & 2 & $\begin{array}{l}\text { CD!3,CD33,CD117,M- } \\
\text { PO,CD45,HLADR }\end{array}$ & AMLMO & $\begin{array}{c}\text { Bone } \\
\text { marrow } \\
\text { transplan- } \\
\text { tation }\end{array}$ \\
\hline 6 & 45 & Female & Gum bleed & 10.2 & 1.5 & 4 & 14 & 7 & 1 & $\begin{array}{l}\text { CD!3,CD33,CD117,M- } \\
\text { PO,CD45,HLADR }\end{array}$ & AMLM4 & Follow up \\
\hline 7 & 43 & Male & Pallor & 5.6 & 1 & 2 & 20 & 11 & 2 & $\begin{array}{l}\text { CD!3,CD33,CD117,M- } \\
\text { PO,CD45,HLADR }\end{array}$ & AMLM1 & Follow up \\
\hline 8 & 45 & Male & Fever & 7.8 & 2 & 2 & 21 & 10 & 2 & $\begin{array}{l}\text { CD!3,CD33,CD117,M- } \\
\text { PO,CD45,HLADR }\end{array}$ & AMLMO & Follow up \\
\hline 9 & 48 & Female & Pallor & 4.6 & 1 & 4 & 14 & 11 & 1 & $\begin{array}{l}\text { CD!3,CD33,CD117,M- } \\
\text { PO,CD45,HLADR }\end{array}$ & AMLM4 & Death \\
\hline 10 & 45 & Male & Fever & 10 & 2 & 2 & 21 & 7 & 1 & $\begin{array}{l}\text { CD!3,CD33,CD117,M- } \\
\text { PO,CD45,HLADR }\end{array}$ & AMLM1 & Follow up \\
\hline 11 & 42 & Male & Pallor & 6.5 & 1.5 & 2 & 20 & 16 & 1 & $\begin{array}{l}\text { CD!3,CD33,CD117,M- } \\
\text { PO,CD45,HLADR }\end{array}$ & AMLMO & $\begin{array}{c}\text { Bone } \\
\text { marrow } \\
\text { transplan- } \\
\text { tation }\end{array}$ \\
\hline 12 & 51 & Female & Icterus & 5.5 & 1 & 1 & 11 & 11 & 1 & $\begin{array}{l}\text { CD!3,CD33,CD117,M- } \\
\text { PO,CD45,HLADR }\end{array}$ & AMLM4 & Follow up \\
\hline 13 & 45 & Male & Pallor & 10.2 & 2 & 2 & 20 & 12 & 2 & $\begin{array}{l}\text { CD!3,CD33,CD117,M- } \\
\text { PO,CD45,HLADR }\end{array}$ & AMLM1 & Follow up \\
\hline 14 & 45 & Male & Fever & 5.6 & 1.5 & 3 & 13 & 12 & 1 & $\begin{array}{l}\text { CD!3,CD33,CD117,M- } \\
\text { PO,CD45,HLADR }\end{array}$ & AMLMO & Follow up \\
\hline 15 & 44.5 & Female & Pallor & 7.8 & 1 & 1 & 14 & 31 & 1 & $\begin{array}{l}\text { CD!3,CD33,CD117,M- } \\
\text { PO,CD45,HLADR }\end{array}$ & AMLM4 & Death \\
\hline 16 & 41.5 & Male & Fever & 4.6 & 2 & 2 & 20 & 11 & 2 & $\begin{array}{l}\text { CD!3,CD33,CD117,M- } \\
\text { PO,CD45,HLADR }\end{array}$ & AMLM1 & Follow up \\
\hline 17 & 35 & Male & Pallor & 10 & 1 & 1 & 15 & 11 & 1 & $\begin{array}{l}\text { CD!3,CD33,CD117,M- } \\
\text { PO,CD45,HLADR }\end{array}$ & AMLMO & Follow up \\
\hline 18 & 45 & Female & Gum bleed & 6.5 & 2 & 2 & 20 & 6 & 2 & $\begin{array}{l}\text { CD!3,CD33,CD117,M- } \\
\text { PO,CD45,HLADR }\end{array}$ & AMLM4 & Follow up \\
\hline 19 & 43 & Male & Pallor & 5.5 & 1.5 & 5 & 15 & 11 & 1 & $\begin{array}{l}\text { CD!3,CD33,CD117,M- } \\
\text { PO,CD45,HLADR }\end{array}$ & AMLM1 & Death \\
\hline 20 & 44 & Male & Fever & 10.2 & 1 & 1 & 18 & 10 & 1 & $\begin{array}{l}\text { CD!3,CD33,CD117,M- } \\
\text { PO,CD45,HLADR }\end{array}$ & AMLMO & Follow up \\
\hline 21 & 43 & female & Pallor & 5.6 & 2 & 2 & 20 & 11 & 2 & $\begin{array}{l}\text { CD!3,CD33,CD117,M- } \\
\text { PO,CD45,HLADR }\end{array}$ & AMLM4 & $\begin{array}{c}\text { Bone } \\
\text { marrow } \\
\text { transplan- } \\
\text { tation }\end{array}$ \\
\hline 22 & 45 & Male & Fever & 7.8 & 1.5 & 4 & 14 & 10 & 1 & $\begin{array}{l}\text { CD!3,CD33,CD117,M- } \\
\text { PO,CD45,HLADR }\end{array}$ & AMLM1 & Follow up \\
\hline 23 & 42 & Male & Pallor & 4.6 & 1 & 1 & 21 & 16 & 1 & $\begin{array}{c}\text { CD!3,CD33,CD117,M- } \\
\text { PO,CD45,HLADR }\end{array}$ & AMLM5 & Follow up \\
\hline 24 & 44 & female & Icterus & 10 & 2 & 2 & 21 & 11 & 2 & $\begin{array}{l}\text { CD!3,CD33,CD117,M- } \\
\text { PO,CD45,HLADR }\end{array}$ & AMLMO & Follow up \\
\hline 25 & 8.5 & Female & Pallor & 7.8 & 1 & 2 & 21 & 14 & & $\begin{array}{l}\text { CD!3,CD33,CD117,M- } \\
\text { PO,CD45,HLADR }\end{array}$ & TALL & Death \\
\hline 26 & 7.5 & Male & Fever & 4.6 & 2 & 2 & 20 & 15 & 1 & $\mathrm{CD} 20, \mathrm{CD} 79, \mathrm{CD} 45, \mathrm{CD} 19$ & B ALL & Follow up \\
\hline 27 & 8 & Male & Fever & 10 & 1.5 & 3 & 23 & 15 & 1 & $\mathrm{CD} 7, \mathrm{CD} 3, \mathrm{CD} 45, \mathrm{CD} 38$ & TALL & Follow up \\
\hline 28 & 9 & Male & Fever & 6.5 & 1 & 1 & 15 & 11 & 2 & $\mathrm{CD} 20, \mathrm{CD} 79, \mathrm{CD} 45, \mathrm{CD} 19$ & B ALL & Death \\
\hline
\end{tabular}


Citation: Mukherjee T, Pramanik S, Dutta R (2016) Acute Leukemia with Atypical Clinical Presentation Posing Diagnostic Dilemma. J Hematol Blood Transfus Disord 3: 010.

- Page 3 of 4 -

\begin{tabular}{|c|c|c|c|c|c|c|c|c|c|c|c|c|}
\hline 29 & 7 & Male & $\begin{array}{c}\text { Cervical } \\
\text { ymphade- } \\
\text { nopathy }\end{array}$ & 5.5 & 2 & 2 & 22 & 11 & 1 & CD7,CD3,CD45,CD38 & T ALL & Follow up \\
\hline 30 & 8 & Female & $\begin{array}{c}\text { Dyspnea } \\
\text { with } \\
\text { mediastinal } \\
\text { mass }\end{array}$ & 10.2 & 1.5 & 4 & 14 & 7 & 2 & CD20,CD79,CD45,CD19 & B ALL & $\begin{array}{c}\text { Bone } \\
\text { marrow } \\
\text { transplan- } \\
\text { tation }\end{array}$ \\
\hline
\end{tabular}

Table 1: Details of patients of hypocellular acute leukemia.

duration we did not come across bone marrow necrosis in any case. In our study the follow up is being continued at 3 years so survival pattern is not elucidated (Table 1).

To mention some of the atypical cases for example a 42 years male patient presented with fever of unknown origin, weakness of 3 months duration. On examination, he was pale looking but there were no lymphadenopathy or organomegaly. Complete blood count revealed hemoglobin of $6.0 \mathrm{gm} / \mathrm{dl}$, WBC count of $1500 / \mathrm{mm}^{3}$ and platelets of $20000 / \mathrm{mm}^{3}$. Peripheral blood showed pancytopenia but there were no blasts. Bone marrow aspirate smears showed myeloblasts which were large cells with scant to moderate amount of cytoplasm, openedup chromatin and conspicuous nucleoli and megakaryocytes were not seen in the aspirate smears and these blasts were cytochemically positive for Myeloperoxidase (MPO). Based on all these features, a tentative diagnosis of acute myeloid leukemia French-American-British (FAB) subtype M2 (AML-M2) that is WHO diagnosis of Acute myeloblastic with maturation, was made based on blast morphology and maturation which was subsequently confirmed by flow cytometry. Bone marrow biopsy showed hypocellular marrow spaces with clusters of blasts in places. Another case of mention and interest is a 5 years old girl presenting with a mediastinal mass and anemia. Hemoglobin of $5.0 \mathrm{gm} / \mathrm{dl}, \mathrm{WBC}$ count of $1,500 / \mathrm{mm}^{3}$, and platelet count of $30,000 / \mathrm{mm}^{3}$. Peripheral blood smear examination revealed pancytopenia and did not reveal blasts. Bone marrow aspirate and imprint smears were hypocellular and hematopoietic elements were replaced by blasts which were of intermediate size, had moderate cytoplasm, opened-up nuclear chromatin and 1 to 4 prominent nucleoli. Blasts stained positive with PAS stain. Bone marrow biopsy showed hypocellularity with blasts only. Flow cytometry confirmed diagnosis of acute lymphoblastic leukemia with CD20, CD19, CD10 and Terminal Deoxynucleotidyl Transferase (TDT) immunostain being positive in flow study and bone marrow biopsy. Treatment of acute myeloid leukemia was by induction with $3+7$ regime with Cytarabine and daunorubicin and consolidation with Cytarabine. For acute lymphoblastic leukemia treatment was induction by Vincristine, prednisolone, daunorubicin and L Asp and CNS prophylaxis with methotrexate. Maintenance with methotrexate, 6mercaptopurine, vincristine and prednisolone and intensification with cytarabine and daunorubicin $7+3$ based on the blood cell counts.

\section{Discussion}

Acute leukemia presenting as hypocellular leukemia is atypical in presentation and poses diagnostic dilemma and is defined as less than $20 \%$ of hematopoietic elements in the bone marrow. Hypocellular Acute Lymphoblastic Leukemias (ALL) occur in children and hypocellular AML in adults [1-2]. In our study out of total 30 cases of hypocellular acute leukemia, twenty five $(n=25)$ of the thirty cases of hypocellular leukemia were AML with median age $44.36 \mathrm{yrs}$ and male to female ratio of 2:1 and most common presenting complaint of anemia and five cases of hypocellular ALL $(n=5)$ with median age 8 yrs and male to female ratio of $4: 1$ and most common presenting complaint being fever.

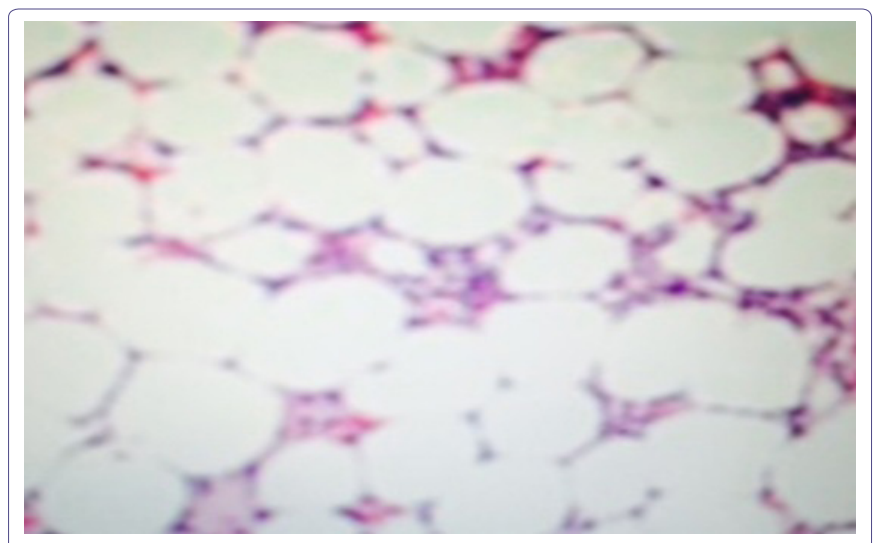

Figure 1: Showing hypocellular bone marrow biopsy.

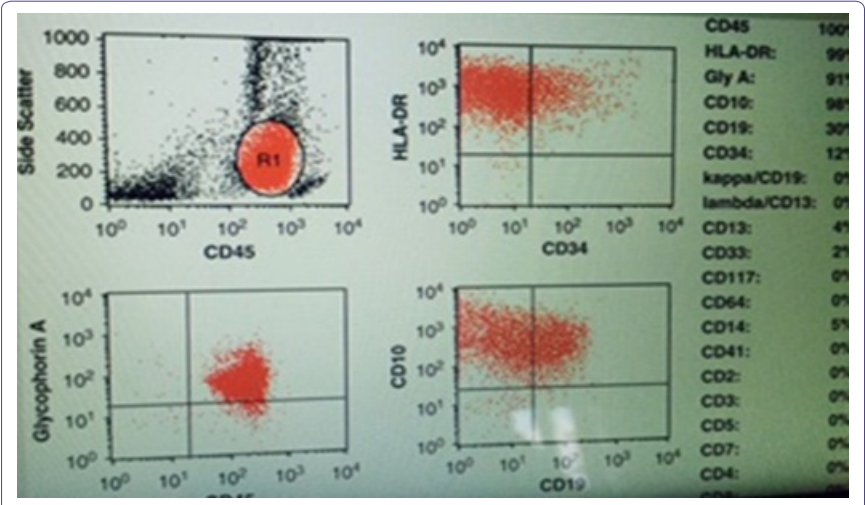

Figure 2: Showing flow cytometry in acute leukemia

Nagai et al., [3] laid the diagnostic criteria of hypocellular atypical leukemia as pancytopenia with blasts \pm in peripheral blood; less than $40 \%$ bone marrow hypocellularity; more than $30 \%$ blasts in bone marrow of all nucleated cells; and myeloid phenotypes of leukemic blasts by myeloperoxidase staining and/or immunophenotyping. In our study out of the 30 cases thirteen cases had less than $20 \%$ blasts in the bone marrow and final diagnosis was rendered by flow cytometry.

In our study out of total 30 cases of hypocellular AML twenty five cases were in age range of 35-51 yrs. Acute lymphoblastic leukemias presented in children $n=5$ of age range $7.5-9$ years. Although the majority of hypocellular acute leukemias are of myeloid type, rare case reports of hypocellular ALL are reported in the literature [4]. Hypocellular ALL usually presents in children but cases in elderly have been documented [5].

Tuzuner et al., studied fourteen cases of hypocellular acute leukemia and they found median age to be 72 yrs whereas in our study the age is comparatively less and the median peripheral blood blast count was $2 \%$ in their study which is comparable to our study in which the median blast is $3 \%$ [6].

In our study of 30 cases of hypocellular acute leukemia in three years duration we did not come across bone marrow necrosis but have 
seen grade 1 and grade 2 fibrosis. Jain et al., studied bone marrow necrosis in their study and has seen grade 1 necrosis in the bone marrow biopsy [7].

In our study the follow up is being continued at 3 years with death in six cases and patients on regular follow up at three years but five years survival pattern is not elucidated whereas Beard et al., [8] and Needleman et al., [9] have studied that hypocellular leukemia patients achieve a good response to therapy.

The question of pathogenesis of the hypocellularity remains speculative. It is unclear whether the leukemia is secondary to the hypocellularity or if it is the primary event. It has been suggested that leukemia cell populations inhibit myelopoiesis through a humoral mechanism. Alternatively, an increased susceptibility of myeloid precursors to the inhibitor in older patients might play a role in the genesis of hypoplasia. Kröber et al., studied two cases of adult hypocellular acute leukaemia with lymphoid differentiation [4] whereas in our study of thirty cases five were of acute lymphoblastic type.

Berdeaux et al., [10] studied twenty-two cases of hypocellular acute leukemia and did multivariate survival analysis however we have not done the survival analysis and the patients are on follow up at 3 years.

\section{Conclusion}

Hypo cellular acute leukemia is not a very uncommon condition but it is difficult to diagnose and differentiate from other entities like hypoplastic myelodysplastic syndrome and a plastic anemia due to infrequent presence of blasts in peripheral blood and bone marrow and high index of suspicion is required to subject for immune phenotypic and flow cytometric antibody tests for prompt diagnosis and intervention which is life saving.

\section{References}

1. Vardiman JW, Harris NL, Brunning RD (2002) The World Health Organization (WHO) classification of the myeloid neoplasms. Blood 100: 2292-2302.

2. Bennett JM, Orazi A (2009) Diagnostic criteria to distinguish hypocellular acute myeloid leukemia from hypocellular myelodysplastic syndromes and aplastic anemia: recommendations for a standardized approach. Haematologica 94: 264-268.

3. Nagai K, Kohno T, Chen YX, Tsushima H, Mori H, et al. (1996) Diagnostic criteria for hypocellular acute leukemia: a clinical entity distinct from overt acute leukemia and myelodysplastic syndrome. Leuk Res 20: 563-574.

4. Kröber SM, Horny HP, Steinke B, Kaiserling E (2003) Adult hypocellular acute leukaemia with lymphoid differentiation. Leuk Lymphoma 44: 1797-1801.

5. Aref Al-Kali, Sergej Konoplev, Erpei Lin, Tapan Kadia, Stefan Faderl, et al. (2012) Hypocellular acute myeloid leukemia in adults: analysis of the clinical outcome of 123 patients. Haematologica 97: 235-240.

6. Tuzuner N, Cox C, Rowe JM, Bennett JM (1995) Hypocellular acute myeloid leukemia: the Rochester (New York) experience. Hematol Pathol 9: 195-203.

7. Jain D, Singh T, Kumar N (2009) Hypocellular acute myeloid leukemia with bone marrow necrosis in young patients: two case reports. J Med Case Rep 3: 27 .

8. Beard ME, Bateman CJ, Crowther DC, Wrigley PF, Whitehouse JM, et al. (1975) Hypoplastic acute myelogenous leukaemia. Br J Haematol 31: 167176.

9. Needleman SW, Burns CP, Dick FR, Armitage JO (1981) Hypoplastic acute leukemia. Cancer 48: 1410-1414.

10. Berdeaux DH, Glasser L, Serokmann R, Moon T, Durie BG et al. (1986) Hypoplastic acute leukemia: review of 70 cases with multivariate regression analysis. Hematol Oncol 4: 291-305. 